\title{
USING PRINCIPLE OF COMPLEMENTARITY WHEN DIAGNOSING COMPLEX LOGISTIC ACTIVITIES BY APPLYING ALTERNATIVE APPROACH
}

\author{
Rostislav Kopytov ${ }^{1}$, Lev Faingloz ${ }^{2}$, Konstantins Cernavskis ${ }^{3}$ \\ Transport and Telecommunication Institute \\ Lomonosova str.1, LV-1019, Riga, Latvia \\ ${ }^{1}$ E-mail: rkopitov@tsi.lv \\ ${ }^{2}$ E-mail: lev.faingloz@tsi.lv \\ ${ }^{3}$ University of Latvia, Faculty of Economics and Management \\ Aspazijas str. 5, LV-1050, Riga, Latvia \\ E-mail:kon.cern@inbox.lv
}

\begin{abstract}
The paper considers the problem of obtaining new data in process of diagnostics of a recognized transportation company. Such knowledge should not contradict to existing theories and objective means, but should be aimed instead at improving the diagnoses issued. By investigating the methodological problem by virtue of the principle of complementarity, the goals of making fundamental changes are achieved without disturbing the efficiency of the enterprise activities.
\end{abstract}

Keywords: uniformity, integrity, value-based management, ratio analysis, object domain, compensatory measures

\section{Introduction}

This methodologically-orientated investigation considers the principle of complementarity when diagnosing the activity of a transportation enterprise. Such a principle is based on the property of reproduction of integrity of enterprise financial status within a definite period of the enterprise activities. When applying complementarity principle, some mutually exclusive "additional" classes of notions must be used in process of interpretation of complicated situations. In particular, we deal with acquisition of new experimental data describing enterprise value in the long run. Such data is accumulated in process of presenting a data set on a system of coefficients describing sustainability of enterprise operation within a short term. Using complementarity principle allows one to set equivalence existing between two classes of notions. On the one hand, we mean the enterprise value integrating the enterprise's activities covering a ten-year period; on the other hand, the values of more than twenty coefficients calculated annually are investigated. The two classes of notions enable one to make a complex description of contradictory situations in two various cognition domains: general activity within a sufficiently long period, and piecemeal actions performed within a year's time. In the first case, decision-making is based on deductive analysis; in the second case, we deal with an opposite approach - i.e., inductive analysis performed on a short-term basis.

In our interpretation, complementarity principle expresses a change in understanding of the subject of knowledge, which is necessary when diagnosing activities of an enterprise. Such interpretation implies that we deal with two different slices, with each of them being set through different prisms of accepted abstract and empirical tools. At the same time, we avoid realizing the realities in its "precise form", and focus on approximations made by experts instead. Such representations allow one to become cognizant of one and the same process investigated under mutually exclusive conditions. We interact with one and the same specific object, with respect of which, however, two different contents are formed according to a known pattern. Moreover, those contents are reproduced in various properties. The fact of the object properties manifesting themselves in different ways is based on legitimacy and equal status of two scientific descriptions of the object. Such descriptions are made on the basis of two different theories representing the same object and the same object domain. 
It is important to emphasize that one and the same object domain is described by two different theories according to the complementary principle. In this case, the classic theory of ratio analysis and the theory of value-based management are used. Characterizing the first of those theories, we have to mention well-known methodologies for financial diagnostics by Altmann, Olivier, Blank, Kovalev et al. [1-4], which are expanded in the context of balance and sustainability by some papers of Kaplan and Norton, Jones, van Horn and Vakhovich, Finnerty and Chang, etc. [15-24]. The second theory is developed on the basis of investigations performed by Copeland, Coller, Murin, Doyle, Dolgoff, Gryaznova, Egerev, Ivashkovskaya and others [25-32].

The two theories differ in their source positions. The source positions are variables characterizing things taken as undefined magnitudes - i.e., value and sustainability state. The two theories are investigated by way of constructing mathematical models using various branches of mathematics differential equations, theory of chance, games theory, etc. At that, interpretation of simulation results of the same phenomena described by one process using different mathematical tools, yields statements, which are close to each other, but, nevertheless, comes to different conclusions. In this research paper, the revealed contradiction is used as a supplement to complementarity principle. Compensatory measures put forward by one of those theories are considered as basic requirements to the creation of compensatory mechanisms applied within the framework of the other. The compensatory mechanisms application results are checked in the context of improvement of the enterprise activities diagnostics. Thus, the goal of research is posed which consists of using different sets of compensatory diagnostic measures to complement two different theories. The object of diagnostics is activity, while the subject of diagnostics is the process by virtue of which the diagnosed activity should be described unequivocally. Within the framework of this research paper, one of the authors (Lev Faingloz) has introduced the notion of complex logistic activity.

\section{The Unity of Complex Logistic Activity and Complex Logistic Process}

Any activity constitutes a totality of sequential operations which are individual actions. Objects of activity are actual actions consisting of operations. As a result of the notions of activity investigated in the paper [34-39] it has become necessary - in process of diagnosing a certain activity - not only to present integrated activity fairly as a system of chains forming it, but also to define a precise name for the activity. It was determined in process of the investigation conducted within the context of the abovementioned aspects that any such activity should be of integrated nature and should extend from the moment of occurrence of finished products. As far as a name is concerned, the category "logistic activity" suggested by Igor Ansoff [40] may be best qualified as integral activity. This author rightfully considered as the Founding Father of the notion of strategy [38] has defined logistic activity as a detailed stepwise transformation of resources into products. This implies that it is referred to an integrated tool of management supporting the achievement of strategic goals of business organization at the expense of an efficient management of actions allowing one to perform optimal operations of product flow advance. In terms of management science, such an activity is not integral one, since it does not take into account any actions taken from the moment of shaping the idea to development of the strategic goal; furthermore, actions taken after the output of final products are neglected. In this paper it is suggested to expand the view on logistic activities, setting therein the effect of transformation of a certain idea into the final product characterizing a certain change in the management system performed. Let us call such a kind of activity a complex logistic activity. To interpret any activity, it is supplemented by the process which is a description of integrated activity made according to uniform requirements. By analogy, such a process will be called an integral logistic process. Therefore, the management system development and change stand, on the one hand, as a complex logistic activity irrespective of people, which seizes their occupation and compels it to its spontaneous laws of development, - and, on the other hand, as an integral logistic process implying a conscious and purposeful behaviour of people united into a specific structure. Such a structure allows one to adjust the description to reality, within the framework of which, correspondence between elements of the activity and the process is maintained at the level of requirements posed (Fig. 1). 


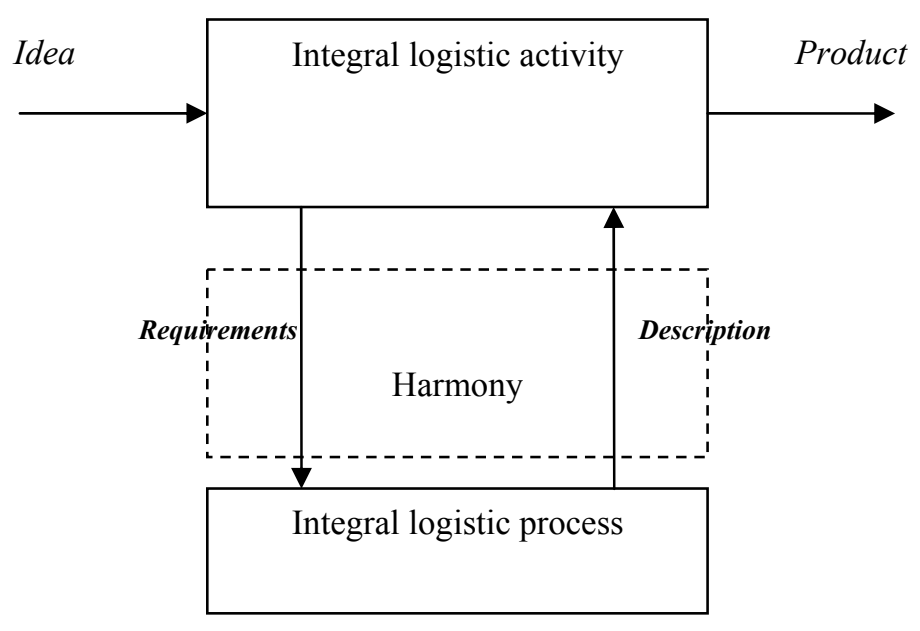

Figure 1. Unity of integral logistic activity and integral logistic process

The designated correspondence is not only reduced to supplementing the integrated logistic activity with the integrated logistic process but is connected with possessing some information on integral activity. Such information should be sufficient to build a unique process. The availability of reliable information meeting the requirements allows one not to avoid any errors in the process that would materially and adversely affect the efficiency of the activity. That's exactly why the primary concern of creating an effective management system is achieving readiness to timely refutation of discrepancies revealed between the description and the requirements. Such readiness provides for a harmony of integrity and unity of the management system. The system manageability manifests itself in proportion to removal of uncertainty eliminated in process of additional complication of multivariate structure of communication and relations. The multivariate structure requires understanding of the place occupied by the principle of complementarity within the general system of management principles.

\section{Research Methodology}

The methodology of this research paper is based on looking for a new knowledge enabling one to organize diagnostics of integral logistic using complementarity principle. Fig. 2 shows the place of complementarity principle within the diagnostics system. This diagram, wherein complementarity principle is the core item, has a holistic foundation with four faces.

When considering the first face of integrity, the determinism principle should be taken into account. According to that principle, all forms of actually existing interrelationships between phenomena are eventually shaped, based on the overall active causality, outside of which not a single phenomenon of reality exists, including events called stochastic; the totality of those events reveals statistical laws. Integrated logistic activity and integrated logistic process are studied under the conditions of removal of uncertainty.

The second face of integrity claims for taking into account the conformity principle - in particular, the succession of scientific theories. New theoretical constructions are helpful for the development of diagnostics system, but, if they don't correlate with the preceding ones, the system ceases to be integral, and experts and employees will soon stop to understand each other at all. In this case, the theory applied to pose requirements to integral logistic activities should not contradict to the theory of their description applied when studying the complex logistic process.

The third face of integrity is characterized by polarity principle wherein each of the polarities complements another one. Integral logistic activity and integral logistic process are needed to provide for a sustainable balanced operation of an enterprise. Each of theoretical inceptions included into the diagnostics system is built with due consideration for definite rules and each of them gains certain utility due to shortcomings of another one. Provisions of each inception should be expressed with the same freedom and substantiated with equal credibility. Otherwise neither of the two will be preferred. 


\section{The determinism principle}

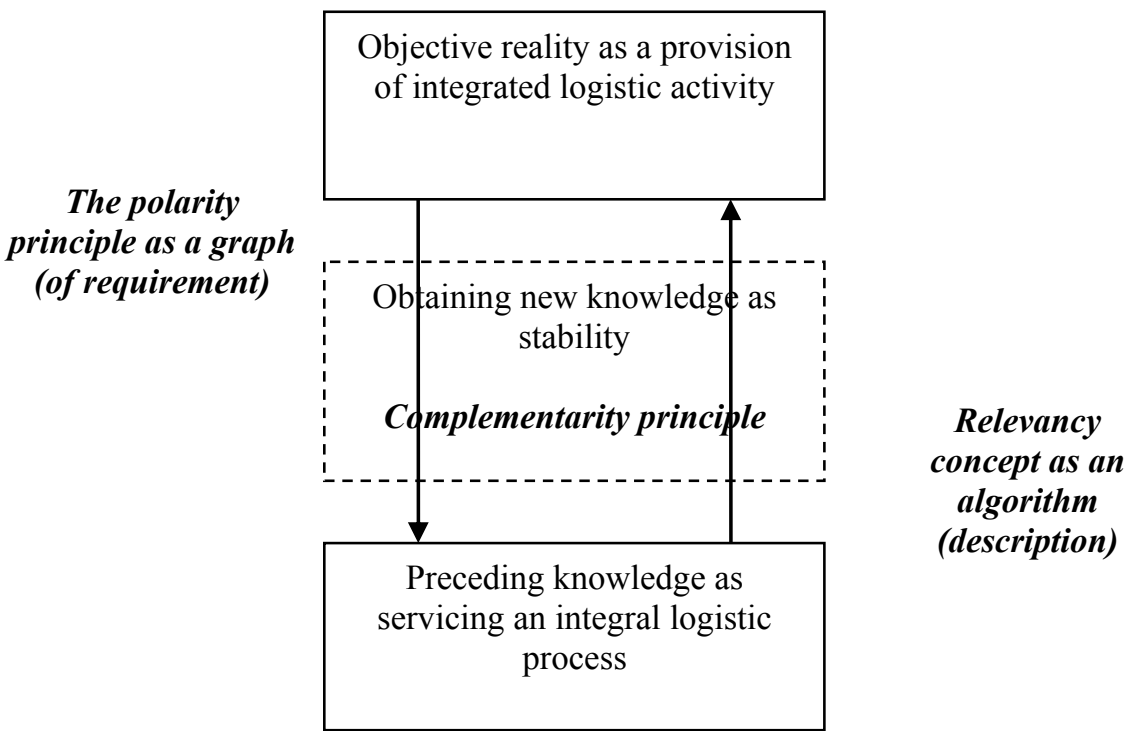

\section{Conformity \\ principle}

Figure 2. The place of complementarity principle within diagnostics system

The fourth face of integrity is based on the relevancy concept which depends on living conditions and the environment. Integral logistic activity and integral logistic process should be associated with the context that is determined by observation circumstances.

The four faces of the integral whole are reflected in usual interpretation of complementarity $[37,38,41,42]$ under which boundary conditions of the enterprise existence are defined. Such conditions having polar attributes (an energy-pulse picture of integral logistic activity and a space-time picture of integral logistic process) yield a third state in the interval between them - as a synthesis with a new attributes (new knowledge under Design Technical Merit in the form of a graph and an algorithm.

In our case, the integral logistic activity complements to the whole the integral logistic process which is opposing with respect to the activity, and vice versa. Thus, compensatory measures of one theory, taken in practice, should be complemented with another theory. Let's assume that the ratio analysis theory at the level of complex logistic activity suggests passing some economic reforms. In this case, ethic norms should be studied within the framework of value-based management theory, at the level of an integral logistic process. Therefore, classic schemes of well-known theories are complemented with spontaneity of benchmark circumstances brought about by taking non-traditional measures from other theories.

The highlighted two integers are considered as supplements but in no way as "not good" or "bad". In process of the complement, one of the elements is given tacit preference. This is connected with the fact that each phenomenon is not perceived by us in its "pure form" but rather through a definite intention. Exactly through the prism of that intention, reflection of reality takes place as a certain condition presented in the form of a set graph. Such a graph represents integral units of problem-heuristic direction. Imperfection, incompleteness, and uncertainty are typical features of such a unit; elimination of these aspects is accomplished at the lowest level. This takes place in the process of final debugging of algorithm, performed under refining conditions where elementary units of scientific knowledge of classic theory are used.

The methodology considered has been applied when investigating the activity of a European transportation company. The factual material exploration period is 10 years: from 2001 to 2010 . The official data of the Register of enterprise are used - specifically, the published financial reporting data of a wellknown carrier. 


\section{Diagnostics of Company State Relying on the Tools of Value-Based Management}

Managing the integral logistic process with the diagnostics of integral logistic activity is exercised, based on the enterprise value $\widetilde{P} v_{\text {project }}$. The diagnostics procedure is reduced to evaluation of factors forming the enterprise values:

$$
\widetilde{P} v_{\text {project }}=\widetilde{P} v_{\text {project }}\left(\widetilde{F}_{1}, \ldots, \widetilde{F}_{i}, \ldots\right) \text {, }
$$

wherein $\widetilde{F}_{i}$ is the i-th factor of value.

Let us split the value into two components: the non-random component (it is designated by original brackets $\langle\langle>\rangle)$ and the random component (it is designated by the symbol $\left.\left\langle\wedge^{\wedge}\right\rangle\right)$ :

$$
\begin{aligned}
& \widetilde{P} v_{\text {project }}=\left\langle P v_{\text {project }}\right\rangle+\hat{P} v_{\text {project }}, \\
& \widetilde{F}_{i}=\left\langle F_{i}\right\rangle+\hat{F}_{i}, \quad i=1, \ldots, N .
\end{aligned}
$$

Further, the solution of the problem is reduced to evaluating the enterprise value at the level of:

- productivity;

- variability.

To evaluate them, calculations of sensitivity index are required. Sensitivity to cost factors should be interpreted as increment or decrease percentage of the enterprise value if the factor value is increased by $1 \%$. All in all, we obtain the expression as follows on the finite number of factors:

$$
\frac{\Delta \widetilde{P} v_{\text {project }}}{\left\langle P v_{\text {proect }}\right\rangle}=\sum_{i=1}^{N} K f_{i} \frac{\Delta \widetilde{F}_{i}}{\left\langle F_{i}\right\rangle},
$$

wherein $\mathrm{N}$ is the number of essential factors;

$K f_{i}-$ sensitivity factor of the $i$-th factor;

$\Delta \widetilde{P} v_{\text {project }}-$ increment of the enterprise value;

$\left\langle P v_{\text {project }}\right\rangle$ - expected value of the enterprise;

$\Delta \widetilde{F}_{i}-$ increment of the $i$-th factor;

$\left\langle F_{i}\right\rangle$ - expected value of the $i$-th factor.

The factor productivity is defined as the degree of increment of the expected factor with respect to the increment of investments made into mechanisms of management to improve integral logistic activities in accordance with the substantiated scenarios of the enterprise development.

The formula for the factor influence upon enterprise value, taking into account sensitivity and productivity of $K p_{i, j}$ for the $i$-th factor by the $\mathrm{j}$-th effort, assumes the form as follows:

$$
\frac{\left\langle\Delta P v_{\text {project }}\right\rangle}{\left\langle P v_{\text {project }}\right\rangle}=\sum_{i=1}^{N} K f_{i} \sum_{j=1}^{M} K p_{i, j} \frac{\left\langle\Delta P_{i, j}\right\rangle}{\left\langle P_{i, j}\right\rangle} .
$$

Variability is defined as a degree of increment of the factor's random component relative to ancillary costs brought about by the occurrence of contingencies. Such contingencies normally lead to changes in the state of the management system. 
As a result, the enterprise value, with due consideration for sensitivity and variability $K c_{i, j}$ for the $i$-th factor by the $\mathrm{j}$-th contingency $\frac{\Delta \hat{C}_{i, j}}{\left\langle C_{i, j}\right\rangle}$ is calculated according to the formula as follows:

$\frac{\Delta \hat{P} v_{\text {project }}}{\left\langle P v_{\text {project }}\right\rangle}=\sum_{i=1}^{N} K f_{i} \sum_{j=1}^{K} K c_{i, j} \frac{\Delta \hat{C}_{i, j}}{\left\langle C_{i, j}\right\rangle}$

The more description and details on the value, productivity and variability calculation according to formulas (1), (2), (3), (4), (5) is developed in the past published works of the article's authors [43]. (see Table 1)

Let us collect the calculated results of sensitivity, productivity, and variability ratios into summary

Table 1. Summary table containing sensitivity, productivity, and variability ratios

\begin{tabular}{|l|c|c|c|}
\hline \multicolumn{1}{|c|}{ Index } & Scenario No 1 & Scenario No 2 & Scenario No 3 \\
\hline Sensitivity ratios & 2,62 & 0,09 & 0,80 \\
\hline Productivity ratios & 3,58 & 0,92 & $-4,53$ \\
\hline Variability ratios & 6,52 & 0,02 & $-17,19$ \\
\hline
\end{tabular}

For the sake of illustration, let us present the data from Table 4 in the form of diagram (see Figure 3):

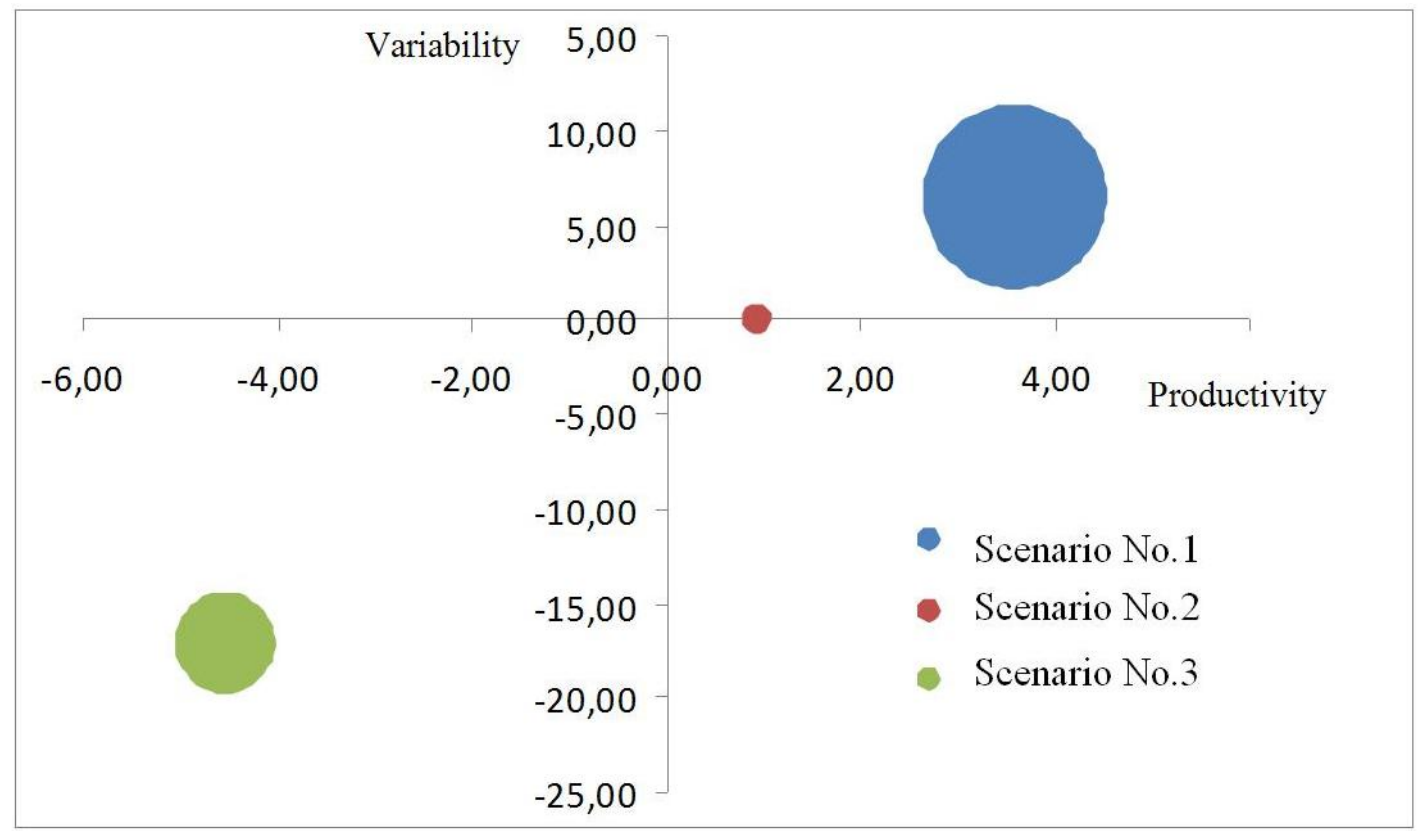

Figure 3. Diagram showing sensitivity, productivity, and variability ratios

According to Figure 3, the most preferred scenario for making improvements is scenario No 1. This decision is taken because Scenario No.1 features the highest sensitivity and productivity as against the second and the third scenarios. It should be noted that the decision was not taken in favour of Scenario No 3 since, despite a high productivity, that scenario features a high variability level, attesting to the highest level of uncertainty. When performing a detailed analysis accompanying investigation of the enterprise value from 2001 to 2010, a set of compensatory measures, shown in Table 2, was suggested. 
Table 2. Suggested compensatory effects within the period from 2008 to 2010

\begin{tabular}{|c|c|c|}
\hline Year & Indices & Steps \\
\hline \multirow[t]{3}{*}{2008} & $\begin{array}{l}\text { Goods and raw materials purchase } \\
\text { expenses }\end{array}$ & Reduction by $9 \%$ \\
\hline & Administrative costs & Reduction by $10 \%$ \\
\hline & Circulating capital (floating assets) & Reduction by $10 \%$ \\
\hline \multirow[t]{2}{*}{2009} & $\begin{array}{l}\text { Goods and raw materials purchase } \\
\text { expenses }\end{array}$ & Reduction by $10 \%$ \\
\hline & Administrative costs & Reduction by $11 \%$ \\
\hline \multirow[t]{2}{*}{2010} & $\begin{array}{l}\text { Goods and raw materials purchase } \\
\text { expenses }\end{array}$ & Reduction by $11 \%$ \\
\hline & Administrative costs & Reduction by $11 \%$ \\
\hline
\end{tabular}

In case of the above-stated compensatory actions were taken, the investigated indices could assume the following form presented on Figure 2.

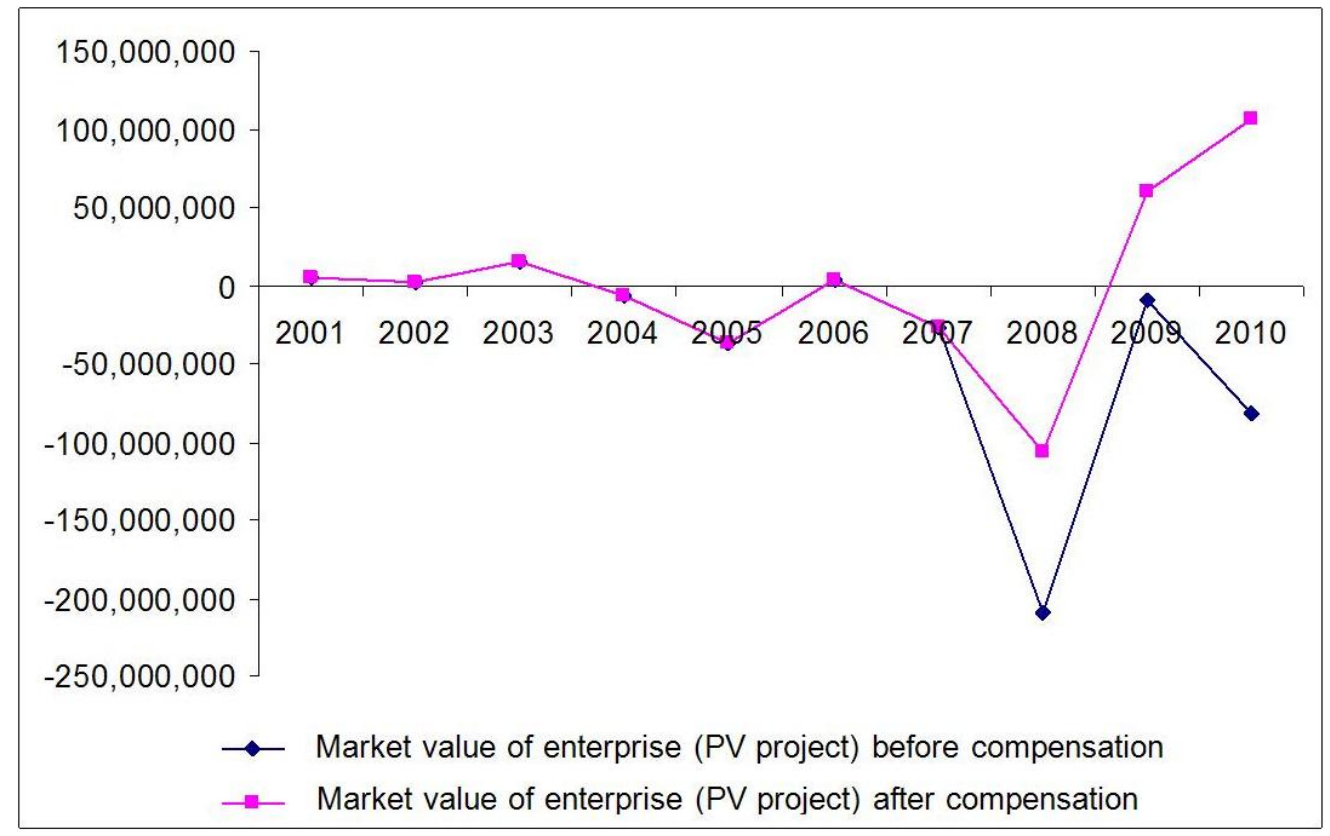

Figure 2. Enterprise value changing diagram within the period from 2001 to 2010 before and after compensatory actions

Analysing the data presented on Figure 2 shows that if the enterprise had started to take compensatory actions suggested in Table 8, it would have managed to cut down losses in value, while in 2009 and 2010 the enterprise would have managed to transfer the value to the positive zone from the negative one.

\section{Diagnostic of Enterprise State Based on Tools of Ratio Analysis}

In process of estimating the financial potential of the enterprise, a group of indices is used reflecting the extent of the enterprise's capabilities of incurring the current financial liabilities and for supporting the optimum capital structure. In this respect, financial conditions of enterprise's activities should be estimated, based on two key indicators: liquidity, financial solvency, and financial instability.

Liquidity and financial solvency are in essence non-identical notions. The integral logistic process investigation has shown that, in practice, situations occur frequently wherein values of liquidity ratio are lying within a preset interval; naturally, the fact attests to a normal financial condition of enterprise. However, such a conclusion may be false, since the largest share percentage within the summarized current assets falls upon illiquid assets or overdue receivables. Therefore, the enterprise under investigation 
is short of funds to repay current payables. So far as the activity is stabilized, a fully developed structure of current (circulating) assets and their formation sources is established at the enterprise. That's why the liquidity ratio values are changing within the framework of preset ranges. Tracing those ratios on a permanent basis would enable one to work out sufficiently good benchmarks to be used subsequently in process of diagnostics of the enterprise activities.

The financial stability of the enterprise is a balanced interaction of activity and processes within a long period of time; the financial stability is provided by performing a multi-level procedure of stabilization, based on financial instability and financial uncertainty ratios.

Based on the assumption that an absolutely stable system can not be encountered in practice, it was decided to measure the degree of instability when describing integral logistic activity. To measure instability and determine its degree, one of the authors of this paper (K. Chernavsky) has suggested two quantitative coefficients to be used. Since direct relationship, feedback, and some barriers exist between integral logistic activities and integral logistic process, the first "financial instability coefficient" is aimed mostly at reflecting the results of activity, while the second "financial uncertainty coefficient" takes the process impacts into account. For that reason, coefficients must not be considered separately when tracing the interaction; each of the coefficients should contain factors describing both the activity and the processes.

The financial instability coefficient is calculated according to the formula as follows:

$N S=X_{1}+X_{2}+X_{3}+X_{4}+X_{5}$

wherein:

$\mathrm{X}_{1}$ - the rate of loss of free cash flow;

$\mathrm{X}_{2}$ - the rate of loss of profit;

$\mathrm{X}_{3}$ - the rate of loss of turnover;

$\mathrm{X}_{4}$ - the rate of loss of circulating assets;

$\mathrm{X}_{5}-$ the rate of loss of equity capital.

The financial uncertainty coefficient is characterized by the formula as follows:

$$
N N=D \times T \times[P-1] \times\left[Y_{1}+Y_{2}+Y_{3}+Y_{4}+Y_{5}\right],
$$

wherein:

D - the depth or level of variability;

$\mathrm{T}$ - the trend or speed of changes;

$\mathrm{P}$ - the probability or predictability of changes;

$\mathrm{Y}_{1}$ - the rate of change of economic standing as a whole;

$\mathrm{Y}_{2}$ - the inflation change rate;

$\mathrm{Y}_{3}$ - the rate of loss of investments;

$\mathrm{Y}_{4}$ - the rate of loss of core markets;

$\mathrm{Y}_{5}$ - the rate of loss of intellectual capital.

Based on the suggested coefficients, the "imbalance quadrants" matrix is developed, characterizing the state of a specific enterprise as of a specific moment of time in terms of the "stability-instability" approach; using this approach can present results of simultaneous diagnostics of activity and process of the given enterprise. With respect to the object under investigation, the integral logistic activity is acknowledged as instable one.

According to the established standards, the operating rates of the enterprise do not fit into the domain of recommended values; using formula (6), this fact attests to financial instability of the enterprise activities within the long-run period from 2001 to 2010. Neither liquidity coefficients, nor financial solvency coefficients and current assets to equity ratio fit into the established standards. Using formula (7) in the diagnostics of financial capacity shows the strong uncertainty of environment, valuating the activity of the enterprise. However, the dynamics of sustainable growth rate (SGR) attests to the fact that 
the enterprise activity has begun to stabilize due to the sales volume increase. Within the period from 2008 to 2010, the sales growth took place at the expense of two main factors: assets turnover increase and capitalization of earnings.

The main results of the countermeasures developed, aimed at changing the obtained critical values of indices, are presented in the form of analytical table shown below (Table 3):

Table 3. The proposed enforcement actions over the period from 2002 to 2010

\begin{tabular}{|c|c|c|}
\hline Year & Essence of change & Compensatory measures \\
\hline 2002 & $\begin{array}{l}\text { Liquidity enhancement; improving current assets to } \\
\text { equity ratio (CAER); provision of stock cover to } \\
\text { a large extent }\end{array}$ & $\begin{array}{l}\text { Taking measures aimed at maintaining financial } \\
\text { solvency; assessing risks of possible investments }\end{array}$ \\
\hline 2003 & $\begin{array}{l}\text { Liquidity enhancement; achieving balance between } \\
\text { the CAER and the main assets; worsening of stock } \\
\text { cover }\end{array}$ & $\begin{array}{l}\text { Achieving balance between liquidity and profitability by } \\
\text { means of increasing sales volumes at the expense of } \\
\text { enlarging the volume of carriage }\end{array}$ \\
\hline 2004 & $\begin{array}{l}\text { Worsening of liquidity; a strong worsening of } \\
\text { CAER }\end{array}$ & $\begin{array}{l}\text { Revising the asset finance policy - first of all, } \\
\text { unmarketable stock (illiquid assets) and overdue } \\
\text { receivables }\end{array}$ \\
\hline 2005 & $\begin{array}{l}\text { Assets leverage optimisation; a strong enhancement } \\
\text { of CAER; worsening of absolute liquidity }\end{array}$ & $\begin{array}{l}\text { Promoting sales by way of price and marketing strategy. } \\
\text { Performing a forecast of Free Cash Flow over a 5-year } \\
\text { horizon }\end{array}$ \\
\hline 2006 & $\begin{array}{l}\text { The growth rate slows down; strong deregulation of } \\
\text { assets leverage; liquidity is maximal }\end{array}$ & $\begin{array}{l}\text { Increasing the rate of turnover of floating assets, } \\
\text { increasing profitability, investing into the main assets } \\
\text { and development projects }\end{array}$ \\
\hline 2007 & $\begin{array}{l}\text { Increasing the growth rate; a successful balancing of } \\
\text { assets leverage; worsening of CAER and liquidity }\end{array}$ & $\begin{array}{l}\text { Achieving balance between the growth rate and liquidity; } \\
\text { finding the optimal proportion for the preset standard of } \\
\text { sustainable growth ratio (SGR). Within at least a 5-year } \\
\text { horizon, drawing a comparison between the estimated } \\
\text { and the actual SGR index }\end{array}$ \\
\hline 2008 & $\begin{array}{l}\text { Critical downfall of growth; ideal leverage and very } \\
\text { bad liquidity }\end{array}$ & $\begin{array}{l}\text { If predictive estimate of the growth rate justifies the } \\
\text { financial resources invested into the assets - performing } \\
\text { the CAER and the borrowed capital restructuring } \\
\text { An urgent fund rising is possible by way of increasing } \\
\text { CAER (bond issuance) and by way of refinancing }\end{array}$ \\
\hline 2009 & $\begin{array}{l}\text { Achieving an intensive growth rate, capitalization of } \\
\text { profit, improvement of financial solvency and } \\
\text { liquidity }\end{array}$ & $\begin{array}{l}\text { Maintaining the balance between profitability and } \\
\text { solvency in the ling run - by way of monitoring of } \\
\text { internal and external changes }\end{array}$ \\
\hline 2010 & $\begin{array}{l}\text { The maximum growth rate at the expense of a strong } \\
\text { reduction of solvency, leverage, and liquidity; } \\
\text { improvement of stock cover share }\end{array}$ & $\begin{array}{l}\text { Providing for the balance of interests of the three groups } \\
\text { of stakeholders: the shareholders. The managerial staff } \\
\text { and the employees. Maintain the growth rate as high as } \\
\text { possible by way of improvement in turnover of assets } \\
\text { and keeping profitability at a preset level }\end{array}$ \\
\hline
\end{tabular}

\section{Income and Outcome Analysis}

It should be noted that, based on the tools used (ratio analysis and value-based management), the same diagnosis has been made: "the enterprise under investigation is under critical situation". This conclusion is conditioned within the framework of the general specific investigation domain.

In process of research performance, two different packages of measures were proposed, which were subsequently used both within the framework of the existing tools and on the basis of the principle of complementarity. In the first case, compensatory measures are conducted within the framework of the existing theory; in the second case, proposals concerning the improvement of integral logistic activity are worked out based on the requirements of one theory, while their testing at the level of an integral logistic process is performed within the framework of an alternative theory.

Different alternatives of synchronization of the theories used are examined in Table 4. 
Table 4. Evaluation of alternatives of compensatory measures

\begin{tabular}{|c|c|c|c|c|c|}
\hline & $\begin{array}{c}\text { Realization } \\
\text { within the } \\
\text { framework of } \\
\text { the value-based } \\
\text { management } \\
\text { theory }\end{array}$ & $\begin{array}{c}\text { Realization } \\
\text { within the } \\
\text { framework of } \\
\text { the ratio } \\
\text { analysis theory }\end{array}$ & $\begin{array}{c}\text { Graphic } \\
\text { presentation* }\end{array}$ & Conclusion & Limitations \\
\hline $\begin{array}{l}\text { Compensatory } \\
\text { measures of } \\
\text { ratio analysis } \\
\text { theory }\end{array}$ & + & - & & Not efficient & No \\
\hline $\begin{array}{l}\text { Compensatory } \\
\text { measures of } \\
\text { ratio analysis } \\
\text { theory }\end{array}$ & - & + & & $\begin{array}{l}\text { Of little } \\
\text { efficiency }\end{array}$ & $\begin{array}{l}\text { Interference } \\
\text { with a stable } \\
\text { process }\end{array}$ \\
\hline $\begin{array}{l}\text { Compensatory } \\
\text { measures of the } \\
\text { value-based } \\
\text { management } \\
\text { theory }\end{array}$ & + & - & & Efficient & $\begin{array}{l}\text { Some } \\
\text { complexities } \\
\text { of application } \\
\text { under } \\
\text { transitional } \\
\text { modes }\end{array}$ \\
\hline $\begin{array}{l}\text { Compensatory } \\
\text { measures of the } \\
\text { value-based } \\
\text { management } \\
\text { theory }\end{array}$ & - & + & & Very efficient & No \\
\hline
\end{tabular}

*The graphic presentation in the Table is demonstrated by intersection of two domains: the dense domain characterized the domain of requirements, while the stroked domain characterized the decisions made. The area of intersection of the two domains characterizes conformity between the requirements and the decisions made. The larger is the intersection domain, the more efficient has been the impact rendered by the compensatory measures upon stabilization of activity.

As it can be seen from the contents of the Table, the most efficient is the fourth alternative wherein the compensatory measures proposed within the framework of the value-based management theory have been applied when estimating the financial potential based on ratio analysis.

\section{Conclusions}

It has been shown in the research paper that using complementarity principle enriches the objective means of diagnosing financial condition by virtue of using alternative theories. This conclusion has been received when investigating the place occupied by complementarity principle within the system of diagnostics. Complementarity principle which was defined as the main one, works within the composition of four principles: determinism, polarity, correspondence, and relevancy. Eventually, an integral logistic activity and integral logistic process synchronization scheme was worked out with due consideration for unity and integrity. Such synchronization not only claimed for substantiated introduction of new concepts but made it necessary to make coordination between the two theories. In the course of coordination, a transition from the formal theory to the content one was made. Presentation of the formal theory, posing requirements to integral logistic activity in the form of an oriented graph, was found. The debugging of the preset algorithm is performed within the framework of the content theory. Using the graphalgorithmic concept by an example of an operating enterprise has shown the efficiency of making basically new generalizations. Such generalizations were built for polar but relevant theories, which enabled one to obtain some refinements fit for tying the value-based management theory and the ratio analysis theory. Thereby, one has managed not only to make an accurate description of a subject domain of the enterprise under investigation by using two different theories, but also to work out compensatory mechanisms for stabilization of the enterprise activities. The compensatory mechanisms application 
results have allowed one to select the best alternative from the standpoint of diagnostics quality improvement.

This research, bearing a methodological character, can be regarded as an applied one; within its framework, some new objective means of diagnostics of enterprise activities can be worked out at various stages of the enterprise's life cycle and under various operating conditions.

\section{References}

1. Altman, E. (1993). Corporate Financial Distress and Bankruptcy. New York: Wiley \& Sons.

2. Altman, E., Hartzell, J. \& Peck, M. (1995). Emerging Markets Corporate Bonds: A Scoring System. New York: Salomon Brothers, Inc.

3. Altman, E. (2002). Bankruptcy, Credit Risk and High Yield 'Junk' Bonds: A Compendium of Writings. Oxford, England and Malden, Massachusetts: Blackwell Publishing,

4. Olve, N., Roy, J., Wetter, M. (1999). Performance Drivers. A Practical Guide to Using the Balanced Scorecard. New York: Wiley \& Sons,

5. Blank, I.A. (2004). Financial Management. Kiev: Nika-Centr. (In Russian)

6. Barnard, C.I. (1948). Organization and Management: Selected Papers. Cambridge, MA: Harvard University Press.

7. Arnold, G. (1998). Corporate Financial Management. London, UK: Pitman Publishing.

8. Kovalev, V.V. (2002). Financial Analysis: Methods and Procedures. Moscow: Finansi i Statistika, (In Russian)

9. Marshall, J. \& Bansal, V. (1992). Financial Engineering. A Complete Guide to Financial Innovation. New York: Institute of Finance.

10. Niven, P. (2002). Balanced Scorecard Step-by-Step. Maximizing Performance and Maintaining Results. Hoboken, NJ, USA: John Wiley \& Sons.

11. Prigozhin, A.I. (2003). Organization Developments' Methods. Moscow: MCFER. (In Russian).

12. Read, C. \& Scheuermann, H. (2003). The CFO as Business Integrator. Chichester, UK: Wiley.

13. Cokins, G. (2004). Performance Management: Finding the Missing Pieces (To Close the Intelligence Gap). Hoboken, NJ, USA: John Wiley \& Sons, Inc.

14. Kopitov, R. (2006). Financial Management and Control. Riga: TTI. (In Russian)

15. Kaplan, R., Norton, D. (1996). The Balanced Scorecard: Translating Strategy into Action. Boston, MA, USA: Harvard Business Review Press.

16. Jones, E. (1994). The Financial Guide to Business Finance. London, UK: Pearson Professional Education.

17. Scott, M. (2000). Cost factors: Manual for managers to reveal value chain development tools. Moscow: Olympia Business. (In Russian)

18. Kaplan, R., Norton, D. (2004). Strategy Maps: Converting Intangible Assets into Tangible Outcomes. Boston, MA, USA: Harvard Business Review Press.

19. Kaplan, R., Norton, D. (2006). Alignment: Using the Balanced Scorecard to Create Corporate Synergies. Boston, MA, USA: Harvard Business School Press.

20. Kaplan, R., Norton, D. (2006). How to Implement a New Strategy Without Disrupting Your Organization. Boston, MA, USA: Harvard Business Review Press.

21. Kaplan, R., Norton D. (2008). Execution Premium. Boston, MA, USA: Harvard Business School Press.

22. Van Horrne, J.,Vachowicz, J. Jr. (2001). Fundamentals of Financial Management. New Jersey: Prentice Hall.

23. Lee, C., Finnerty, J. (1999). Corporative Finance: Theory, Method and Applications. New York: HBJ.

24. Couplend, T., Koller, T., Murrin, J. (1995). Valuation: The Value of Companies: Measuring and Managing. The Value Companies. New York: Wiley \& Sons.

25. Couplend, T., Koller, T., Murrin, J. (1999). Valuation: The Value of Companies: Measuring \& Managing. New York: Wiley \& Sons.

26. Doyle, P. (2000). Value-Based Marketing: Marketing Strategies for Corporate Growth and Shareholder Value Hoboken, NJ, USA: John Wiley \& Sons.

27. Egerev, I.A. (2003). Evaluation of business: The art of management. Moscow: Delo.

28. Gryaznova, A.G. (2005). Business Value. Moscow: Finansi i Statistika.

29. Couplend, T., Dolgoff, A. (2005). Expectations-Based Management: A State-of-the-Art Approach to Creating and Enhancing Shareholder Value. Chichester, UK: Wiley. 
30. Copeland, T. \& Dolgoff, A. (2006). Expectations-Based Management. Journal of Applied Corporate Finance, 18 (2), pp. 82-97.

31. Kopitov, R., Faingloz, L. (2008). Ways of Transforming Aims into Results at Successful Companies. Technological and Economic Development of Economy. Baltic Journal on Sustainability, 14(3), 312-326. DOI: 10.386/1342-8619.2008.14.

32. Kopitov, R. (2009). Managerial principles as the foundation of the control style transformation. In Proceedings of the International Scientific Conference "INSIGHTS INTO THE SUSTAINABLE GROWTH OF BUSINESS (MMRC 2009)”, November 19-21, 2009 (pp. 1-19). Vilnius, Lithuania: ISM University of Management and Economics.

33. Ivashkovskaya, I.V. (2012). Company's Value Modelling. Moscow: INFRA-M. (In Russian)

34. Schedrovitsky, G.P. (1995). Selectas. Moscow: Sch.Kult.Polit. (In Russian)

35. Prigozhin, A.I. (2007). Disorganisation: Causes, Types, Overcoming. Moscow: Alpina Business Books. (In Russian)

36. Neave, H. (1990). The Deming Demission. Tennessee, Knoxville: SPC Press.

37. Novikov, A.M. \& Novikov, D.A. (2010). Science's Investigations Methodology. Moscow: Librkom. (In Russian)

38. Cummings, S. (2005). Recreating Strategy. London, UK: SAGE Publications,

39. Litvak, B.G. (2012). Management Science. Moscow: Delo. (In Russian)

40. Ansoff, I. (1969). Business Strategy. Harmondsworth: Penguin Books.

41. Derrida, J. (1978). Writing and Difference. London: Routledge \& Kegan Paul, Ltd.

42. Teslimov, A. (2011). Business Changes: 9 Rules and 70 Lessons of the Your Business Assigns. Moscow: Eksmo. (In Russian)

43. Kopytov, R., Faingloz, L. (2011). Investigation of Factors Influencing Logistic Activities. In Proceedings of the Conference 'Reliability and Statistics in Transportation and Communication' (RelStat'11), Riga, Latvia, October 19-22, 2011 (pp. 186-200). Riga: Transport and Telecommunication Institute. 